\title{
La justicia militar: una mirada desde la realidad ${ }^{1}$
}

\author{
Military Justice: A View from Reality
}

\section{Daniel José Vásquez Hincapié2 \\ Luz Marina Gil García}

Fecha de Recepción: 8 de abril de 2016

Fecha de Aprobación: 21 de junio de 2016

\section{Resumen}

El estudio de la configuración de las normas en la justicia militar y del contenido de los fallos de los tribunales civiles y militares permiten la realización de una prospectiva de la justicia militar para que, en el caso de suceder un cambio sustancial en la organización sociocultural del país, se logre establecer con probabilidades cercanas a la exactitud, si se continuara el proceso de penalización de las conductas de los militares en favor del mantenimiento de una subordinación, con matices de subyugación, puesto que es posible observar que el Estado sigue reclamando su imperio sobre los ciudadanos, a los cuales con normas, que incluso van en contra de sus propios mandatos constitucionales, les impone la condición obligatoria de defensa del Estado, antes que una posición en contrario como la señalada en el artículo segundo de la Constitución Política de Colombia.

Encontrar ahora las diferencias conceptuales y doctrinarias presentes en la administración de justicia militar puede hacer posible la recuperación del régimen disciplinario militar, que

1 Artículo asociado al Proyecto de Investigación de la Universidad Militar Nueva Granada, DER 1793, Delitos contra el servicio y la disciplina en la justicia penal militar colombiana: una mirada desde la realidad.

2 Investigador principal. Doctor en Derecho de la Universidad San Pablo CEU Madrid, profesor de Derecho Administrativo de la Facultad de Derecho de la Universidad Militar Nueva Granada. Correo electrónico: daniel. vasquez@unimilitar.edu.co

3 Coinvestigadora. Magíster en Derecho Administrativo - UMNG. Profesora de la Facultad de Derecho de la Universidad Militar Nueva Granada. Correo electrónico: luz.gil@unimilitar.edu.co 
gradualmente ha perdido importancia frente a lo penal, haciendo inclusión del militar como persona objeto de la Constitución, con absoluta igualdad de derechos para sus conciudadanos.

Palabras clave: constitución, igualdad, legitimidad, pluralismo, soberanía.

\begin{abstract}
The analysis of setting rules of military justice and the concept of decisions of civil and military courts may allow a likely performance of military justice. In case of a prominent change in the socio-cultural organization of the country, this instance may be able to establish probabilities close to the accuracy, whether there is a process of criminalizing the military conduct to encourage a subordination with subjection traits, since it is possible a State that continues to claim its empire against citizens, which imposes rules even against their own constitutional mandates, a compulsory condition of defense of the State instead of a contrary position provided in the second article of the Colombian Constitution.
\end{abstract}

Establishing conceptual and doctrinaire differences at the administration of military justice may recover the military disciplinary regime, which has lost gradually prominence against some criminal matters, making inclusion possible of military officers as ordinary individuals under the Constitution, with full equality of rights for their fellow citizens.

Keywords: constitution, equality, legitimacy, pluralism, sovereignty.

\title{
INTRODUCCIÓN
}

Las normas jurídicas se transforman en la medida en que suceden cambios sociales a partir de las transformaciones económicas, políticas y culturales que viven pueblos, de manera que se considera consecuente que ad portas de alcanzar una negociación positiva, respecto del conflicto armado en Colombia, es oportuno investigar la posible injerencia en las problemáticas de la justicia penal militar, mediante la revisión de los textos del Código Penal Militar, del Reglamento de Régimen Disciplinario y de las sentencias del Tribunal Superior Militar. Conocer, por ejemplo, los efectos del posible transito del conflicto a la paz y determinar si lo relacionado con los delitos 
militares contra la disciplina y el servicio, se mantendrán dentro de la misma condición, bajo el Régimen Penal Militar o si por el contrario serán considerados como contravenciones juzgadas mediante el Régimen Disciplinario.

El análisis de la temática no es una tarea que simplemente permita presentar un resultado de previsión legislativa para plantear lo que podría ser el futuro Código de Justicia Penal Militar, sino que, por el contrario, permitiría señalar las condiciones de la redacción dentro de otro régimen de normas, además que podría señalar las necesidades de su unificación en la interpretación axiológica.

Aunque parezca una herejía en derecho, no sería posible que cada juez militar interpretara la norma de acuerdo con su leal saber y entender, ya que estaría desvirtuando la existencia de una justicia especializada. En este sentido, cualquier juez de la República pudiera atender los casos militares dando término legal al fuero militar.

Se hará entonces la revisión de algunas sentencias emitidas por el Tribunal Superior Militar, desde el año 2010 hasta la fecha, relacionadas con la disciplina y el servicio, con el fin de establecer los criterios del juzgador en cada proceso y determinar si estos se podrían mantener, en caso de que se produjera un cambio en la situación de orden social en el país.

\section{LA NORMA JURÍDICA Y DISCIPLINARIA MILITAR}

Los bienes jurídicos, el servicio y la disciplina son defendidos por el Estado desde los ámbitos tanto disciplinarios como penales; además, la punibilidad de las conductas, en uno y otro, también contemplan los componentes de tipicidad, antijuricidad (penal) o ilicitud sustancial (disciplinario) y culpabilidad, con la diferencia de que la antijuricidad, en lo penal, se refiere a la lesión o puesta en peligro, sin causa justa, de un bien tutelado por la ley penal (Ley 1407, 2010, art. 17). En lo disciplinario, la ilicitud sustancial corresponde a la afectación de un deber funcional sin justificación alguna (Ley 734, 2002, art. 5).

De esta manera, se pueden establecer diferencias básicas en uno y otro caso: mientras lo penal está a cargo de la Justicia Penal Militar, como una jurisdicción especializa- 
da que se encarga de la investigación y juzgamiento de hechos relacionados con el servicio, cometidos por miembros de la Fuerza Pública en actividad, de acuerdo con lo establecido en el Código Penal Militar (Ley 1407, 2010), el derecho disciplinario hace parte del derecho administrativo sancionador, fundamentado en la relación de sujeción entre el servidor público (y el particular con funciones públicas) y el Estado, es decir, en relación con las funciones de los servidores públicos.

Al respecto, la Corte Constitucional ha manifestado con referencia al derrotero del derecho disciplinario lo siguiente:

"Es por ello que la jurisprudencia constitucional reiteradamente ha sostenido que este derecho se constituye en un elemento básico de la organización estatal y la realización efectiva de los fines esenciales del Estado Social de Derecho" (Corte Constitucional, Sentencia C-769, 1998).

La Constitución Política de Colombia, en su artículo segundo, indica que la principal finalidad de la construcción del Estado es prestar servicios públicos a sus asociados:

"Son fines esenciales del Estado: servir a la comunidad, promover la prosperidad general y garantizar la efectividad de los principios, derechos y deberes consagrados en la Constitución; facilitar la participación de todos en las decisiones que los afectan y en la vida económica, política, administrativa y cultural de la Nación; defender la independencia nacional, mantener la integridad territorial y asegurar la convivencia pacífica y la vigencia de un orden justo. Las autoridades de la República están instituidas para proteger a todas las personas residentes en Colombia, en su vida, honra, bienes, creencias, y demás derechos y libertades, y para asegurar el cumplimiento de los deberes sociales del Estado y de los particulares" (Constitución Política de Colombia, 1991, art. 2).

Para este cometido el Estado es una persona jurídica que debe ser representada, disponiendo para ello de unos servidores públicos con funciones detalladas, de conformidad con la Carta Política "no habrá empleo público que no tenga funciones detalladas en ley o reglamento" (Const., 1991, art. 122), mediante los cuales cumple con sus obligaciones administrativas y dentro de ellas están las correspondientes a las Fuerzas Militares. Pero así mismo, él tiene la obligación de velar porque estas funcio- 
nes sean cumplidas de acuerdo con las facultades que a cada uno se le encomiendan y con aquellas que se establezcan en relación con los asociados y atendiendo a cumplir cabalmente los cánones que le impone el Estado Social de Derecho.

De esta manera, como el Estado no es el destinatario de la norma penal, sino que lo son sus funcionarios, él mismo se ve en la necesidad de establecer, por ello, los derechos a cumplir como los referenciados en los artículos segundo (en relación con el mandato constitucional del deber de servir), y sexto (sobre la responsabilidad) al señalar que "los particulares solo son responsables ante las autoridades por infringir la Constitución y las leyes. Los servidores públicos lo son por la misma causa y por omisión o extralimitación en el ejercicio de sus funciones" (Const., 1991, art. 6). Lo anterior hace que el Estado coloque a sus funcionarios en la posición de garantes del cumplimiento de las obligaciones que ejercen en su representación, bajo la fórmula de las relaciones generales y especiales de sujeción.

Respecto de las Fuerzas Militares, el legislador expidió el Código Penal Militar (Ley 1407, 2010) y el Reglamento de Régimen Disciplinario para las Fuerzas Militares (Ley 836, 2003). Estas normas manifiestan la existencia de esa garantía exigida a los militares en la prestación de sus servicios, de acuerdo con los compromisos que les señala la Constitución y la ley. Particularmente, en el Código Penal Militar, la posición de garante está determinada en el artículo 27 , que reza:

"Acción u omisión. La conducta punible puede ser realizada por acción u omisión. El miembro de la Fuerza Pública que tuviere el deber jurídico de impedir un resultado perteneciente a una descripción típica, cuente con los recursos y medios disponibles y no actuare estando en posibilidad de hacerlo dentro de su ámbito propio de dominio, quedará sujeto a la pena contemplada en la respectiva norma penal, si no concurriere causal de exclusión de responsabilidad. A tal efecto se requiere que tenga a su cargo la protección real y efectiva del bien jurídico protegido o la vigilancia de determinada fuente de riesgo, conforme a la Constitución, la ley o los reglamentos.

Parágrafo. La posición de garante solo se tendrá en cuenta en relación con las conductas punibles que atenten contra la vida e integridad personal y la libertad individual" (Ley 1407, 2010, art. 27). 
Por su parte, en el Reglamento de Régimen Disciplinario, la alusión se especifica en el artículo 27, al afirmar:

\begin{abstract}
"Artículo 27. Compromiso. Es propio del superior aceptar los compromisos institucionales sin acudir a disculpas relacionadas con la escasez de recursos para el cumplimiento de los deberes, cuando la obtención de los mismos se encuentre a su alcance.
\end{abstract}

Corresponde al militar cualquiera que sea su jerarquía, asumir con diligencia su compromiso institucional en el cargo que desempeña y, en situaciones imprevistas, tomar las acciones que correspondan a cada caso y siempre según las normas de la dignidad y el honor.

La negligencia y el desinterés en el cumplimiento de las obligaciones, indican poco valor militar. Subestimar la profesión, demostrar despreocupación por la propia preparación, reducir la actividad del servicio a lo estrictamente necesario, llegar tarde a los actos del servicio, dar excusas infundadas, denotan falta de compromiso institucional y carencia de espíritu militar" (Ley 836, 2003, art. 27).

Tal como se advierte, la posición de garante es exigida por el Estado en materia penal con referencia a las conductas que se relacionan con la vida, la integridad personal y la libertad individual, mientras que en lo disciplinario lo hace en relación con el estricto cumplimiento de las funciones.

Aun así, es necesario entender que un fundamento del poder del Estado es el de determinar los límites en su relación con sus asociados y parte de ello está contemplado en el ordenamiento jurídico al que deben subordinarse las personas que hacen parte de él. Según Bobbio (2006), el Estado mantiene esas normas con las cuales busca preservar su legitimidad "hasta que la ineficacia ha llegado a tal punto que hace probable o previsible la eficacia de un ordenamiento alternativo" (p.125), es decir, hasta donde las normas le hagan posible su gobernabilidad.

A diferencia del sistema colombiano, en Uruguay no existe separación alguna entre el Código Penal Militar y el Código Disciplinario, sino que el Código Penal Militar 
en su artículo 2 clasifica el delito militar según su gravedad en delitos o faltas, ocupándose de estas últimas los militares (art. 61) que aplican los castigos disciplinarios determinados en los Reglamentos del Ejército y la Marina (art. 62).

La legislación española tiene dos sistemas diferenciados y el Código Penal Militar (Ley orgánica 14, 14 de octubre de 2015), ley que taxativamente señala que sus contenidos no contemplan las infracciones disciplinarias y advierte "las infracciones disciplinarias cometidas por los miembros de las Fuerzas Armadas y de la Guardia Civil se regirán por su legislación específica (art. 1)

El Código Militar mexicano trata en el libro segundo sobre los delitos, faltas, delincuentes y penas, clasificando los delitos en el Capítulo I en intencionales y no intencionales o de imprudencia (art.101) y en el Capítulo II las faltas, que dice "serán castigadas de acuerdo con lo que prevenga la Ordenanza o leyes que la sustituyen (art. 104) (Código de Justicia Militar, 1933 -última reforma publicada en el Diario Oficial de la Federación 13 de junio de 2014.)

En Argentina, el Código de Justicia Militar comprende los delitos y las faltas, cuyo Anexo I corresponde al ámbito penal y procesal penal, dejando a partir del Anexo IV el Código de Disciplina de las Fuerzas Armadas y en el Título II las Faltas Disciplinarias, señalando además en el Título IV las atribuciones de los Consejos Generales de Guerra, los Consejos Generales de Disciplina y los Consejos de Disciplina, como los encargados de la administración de los procesos disciplinarios.

\section{LA TIPICIDAD EN LA JUSTICIA MILITAR}

Corresponde al legislador la descripción de las conductas que en su entender desconocen el ordenamiento jurídico, pero, además, debe tener en cuenta las que el Estado le señala como perturbadoras de la convivencia pacífica, porque atentan contra un bien de interés para los individuos y para la sociedad.

En el caso concreto de la justicia militar, por razones de intervención política del Estado, la rigurosidad de la sanción penal se ha impuesto sobre lo disciplinario, a pesar de ser este igualmente severo, por la privación de la libertad con la cual se presume 
cumplida y verdadera justa, constituyendo una grave determinación de desigualdad entre los servidores del Estado, pero también un sistema conveniente de mantenimiento del statu quo de soberanía o imperio del Estado sobre sus servidores, a pesar de que sus propias normas prediquen lo contrario.

Navas Corona (2003) precisa la definición de la tipicidad manifestando que "es la descripción abstracta, clara, precisa y comprensible de la conducta humana, realizada por el cuerpo legislativo del Estado, como su primer elemento del hecho punible y mecanismo de control social" (p. 20).

Sobre los miembros de las Fuerzas Militares, el Estado ha impuesto funciones, inhabilidades y prohibiciones mayores a las que obligan a los demás servidores, con las cuales busca forzar el cumplimiento adecuado de las ocupaciones que les atribuye la Constitución Política o la ley, como también pretende que, con mínimas garantías realice la acción de la fuerza, que es la función generadora de mayor contradicción con el Estado. Esta presión con la que se pretenden establecer comportamientos perfectos en individuos con las mismas falencias culturales y formativas que el resto de la sociedad, llevó al organismo militar a un proceso de vaciamiento de su atribución disciplinaria para entregarla a los jueces, quienes han juzgado y condenado desconociendo lo expresado por la Corte Constitucional que consideró que:

"La respuesta penal debe ser proporcional a la conducta objeto de la sanción, debe ser idónea, operar únicamente cuando no hay otras alternativas, y no debe ser criminógena, es decir, causar más problemas de los que resuelve. Esto sólo es posible si la definición de las políticas criminales se hace a través de una amplia discusión democrática, y no mediante una inflación de normas penales promulgadas apresuradamente" (Corte Constitucional, Sentencia C-599, 1999)

Según lo enseña Galán (2010), con el tipo penal se precisan las conductas que hacen una acción prohibitiva porque perturban la convivencia pacífica o dañan los intereses de los individuos o de la sociedad, además, tienen; entre otras, la función de sistematizar las conductas delictivas según características como la calidad de los sujetos o los bienes jurídicos afectados.

Diferentes decisiones de la Corte Constitucional, como las adoptadas en las Sentencia C-818 de 2005 y Sentencia C-404 de 2001, plenamente aceptadas por la 
Procuraduría General de la Nación en el Concepto 5212 de 07 de septiembre de 2011, señalan que la diferencia en la rigurosidad entre los dos regímenes, penal y disciplinario, hace posible que existan los tipos en blanco, permitiendo al legislador, al determinar la adecuación típica de las conductas delictivas y faltas reprochables, interpretar y aplicar el tipo, de acuerdo con lo que le señala el Estado. Sobre esta teoría la Corte Constitucional establece que se:

"Ha definido un tipo penal en blanco como aquel en que el supuesto de hecho se encuentra desarrollado total o parcialmente por una norma de carácter extrapenal' y agrega que 'la remisión o reenvío del tipo penal en blanco a normas de rango administrativo tiene sus propias reglas" (Corte Constitucional, Sentencia C-121, 2012).

Dado que el tipo penal en blanco remite a otra u otras, según se señaló en la sentencia C-605 de 2006, la remisión que opera en la complementación de este tipo penal puede ser impropia cuando se hace referente a otra disposición legal o propia cuando se hace a normas de jerarquía inferior. Respecto de la remisión estipula que se:

"Debe cumplir cuatro requisitos fundamentales: En primer lugar, la remisión debe ser precisa; en segundo lugar, la norma a la cual se remite debe existir al momento de conformación del tipo penal. En tercer término, la norma de complemento debe ser de conocimiento público y, finalmente, debe preservar, como cualquier norma del ordenamiento, los principios y valores constitucionales" (Corte Constitucional, Sentencia C-605, 2006).

Igualmente, en la Sentencia C-121 de 12 de febrero de 2012, la Corte ha agregado que "el propio Código Penal ha consagrado tipos penales abiertos en los que no existe total precisión de las circunstancias en que la conducta debe realizarse”.

En lo disciplinario, dice la Procuraduría General de la Nación (2011) en el Concepto 5212, también son admisibles las faltas en tipos abiertos, que remiten al complemento normativo de deberes, mandatos y prohibiciones que son aplicables a los servidores públicos. Señala así mismo que "tal admisibilidad en el derecho disciplinario corresponde a la necesidad de salvaguardar el principio de eficiencia de la función pública”. 
Para cerrar el punto del proceso de elaboración de la norma, se tiene en cuenta que tanto a lo penal (Ley 1407, 2010, art. 21) como a lo disciplinario (Ley 734, 2002, art. 27) se llega por acción o por omisión, donde la omisión propia está plenamente descrita en los artículos 115, 119, 145, 148, 149, 158 y 166 de la Ley 1407 de 2010; donde se remite a normas de menor categoría. Los que se refieren a la omisión impropia están descritos y estructurados en el artículo 27, bajo el concepto general de la posición de garante del personal militar en relación con los punibles que atenten contra la vida e integridad personal y la libertad individual, los cuales remiten a normas de categoría superior, es decir, que deben deducirse de un tipo penal de resultado.

Como el Estado tiene el deber de prestar el servicio de defensa y seguridad de las personas, ha dispuesto que las normas jurídicas para asegurar el cabal cumplimiento de tal función, no solo sean garantizadas por la función de garante, sino que, además, empleó la dogmática en la construcción de las normas.

\section{GÉNERO Y ESPECIE}

Al tratar sobre la responsabilidad jurídica sancionatoria, García Amado (2012) hace las siguientes reflexiones:

"La responsabilidad jurídica sancionatoria, que es responsabilidad unida a castigos por la propia conducta dańosa, tiene dos manifestaciones, como hemos dicho, la penal y la administrativa. A ambas son comunes en los sistemas jurídicos de Estado de Derecho una serie de elementos, que suelen venir estipulados en las Constituciones. El más importante es la sumisión al principio de legalidad, que significa que nadie puede ser castigado por una conducta que en el momento de realizarse no esté expresamente prohibida por las normas del sistema jurídico y con una sanción que no sea la que las normas jurídicas prevean para una conducta así. También son imperativas ciertas garantías para esa imputación de responsabilidad y del correspondiente castigo, garantías esencialmente formales y procedimentales, como las relativas a la prueba de los hechos o a la presunción de inocencia, si bien dichas garantías, y hasta el mismo principio de legalidad, tienen alcance distinto en el ámbito penal y en el administrativo" (p.127). 
El caso colombiano no es diferente y los derechos constitucionales de los asociados se constituyen en el límite del Estado para la imposición de las normas jurídicas. Ello implica que los gobernantes apliquen principios de proporcionalidad y legalidad a las que conciernen al ejercicio ordinario de las competencias por parte de sus funcionarios, para que las apliquen y controlen dentro de los mismos principios, de manera que se cumpla lo que Vicenzo Ferrari (1989) determinó como función de legitimación del poder por el derecho, en su libro Funciones del derecho. Para el caso de las Fuerzas Militares, el cumplimiento por parte de sus miembros activos de esta obligación de sujeción al Estado ha sido definida de dos maneras, que a su vez constituyen los bienes jurídicos a defender por la justicia militar, el servicio y la disciplina.

Por servicio se entiende, según lo señala la Corte Suprema de Justicia:

"En relación con el concepto de servicio, tal como sin dificultad surge de la previsión contenida en el estatuto castrense, se tiene que es término referido a los específicos deberes que atañen a los miembros activos de la Fuerza Pública a quienes se asignan labores de dirección o vigilancia" (Corte Suprema de Justicia, Sala de Casación Penal, Rad. 12878).

Y por disciplina también indica que: "Implica la observancia de las normas y órdenes que consagra el deber profesional” (ibíd.).

Por su parte, la Corte Suprema de Justicia, por medio de su Sala de Casación Penal, ha determinado que en relación con los bienes jurídicos que se protegen en la justicia militar, hay una correspondencia de género y especie entre los injustos, de manera tal que la disciplina es el género y el servicio es la especie, haciendo distinción en que:

"Los atentados contra la disciplina pueden predicarse de todos los miembros de las fuerzas militares, las faltas contra el servicio sólo son atribuibles al militar en servicio activo a quien a través de trámites formales previamente establecidos se le haya asignado una función, tarea o cargo específico" (Corte Suprema de Justicia, Sala de Casación Penal, Rad. 12878).

Tal precisión de la Corte Suprema de Justicia tiene importancia en cuanto señala que las transgresiones contra la disciplina pueden instruirse sobre cualquier miem- 
bro activo de las Fuerzas Militares en cualquier tiempo, es decir, en situaciones de conflicto o durante tiempos de paz, a diferencia de las violaciones contra el servicio que requieren que el militar no solo esté activo sino cumpliendo una función o una misión específica, legalmente atribuida.

Se entiende, entonces, que los delitos contra el servicio son todas las trasgresiones que cometen los militares en la realización de sus funciones constitucionales de defensa de la soberanía, la independencia, la integridad territorial y el orden constitucional, a las que además, deben ańadirse los delitos que en cualquier tiempo exigen el deber de presencia como la deserción y el abandono del puesto, porque con ellos se busca garantizar la prestación del servicio y el cumplimiento de la función ${ }^{4}$, quedando lo demás para el ámbito de contenidos de las transgresiones a la disciplina.

Así pues se entiende que el uso ilegitimo e ilegal de la fuerza, para que sea objeto de conocimiento por la Justicia Penal Militar, solo debe relacionarse con la ejecución de las operaciones militares, por lo que se excluye de ella toda tarea del planeamiento y con mayor precisión, toda tarea administrativa anterior como el entrenamiento.

Sin embargo, no queda ahí la posibilidad de interpretación, puesto que el mismo Tribunal Superior Militar incluye todas las actividades logísticas y administrativas como propias del servicio para el cumplimiento de la función constitucional, con lo que las transgresiones a la disciplina solo serían aquellas, producto de la relación particular entre personas miembros de las Fuerzas Militares. 5 . Así lo establece el Tribunal Superior Militar cuando con ponencia del Magistrado Suarez Aldana, manifiesta sobre el concepto de servicio que:

4 Tribunal Superior Militar, MP. Suárez Aldana Camilo Andrés, Proceso 156500-730-XIV-392- PNC, p. 16; en donde manifiesta que "Lo que busca el legislador con el delito de Abandono del Puesto no es la protección de un espacio geográfico determinado, entendido éste desde la perspectiva ontológica, sino garantizar la prestación de un servicio y el ejercicio de la función”, explicación analógicamente aplicable a la deserción.

5 Tribunal Superior Militar, MP. María Paulina Leguizamón Zárate, Proceso 1560 54-4451-XIV-340 EJC, p. 14; donde respecto a los delitos contra el servicio manifiesta “(...) olvida que el Servicio y todas las actividades operacionales, logísticas y administrativas, que lo integran enervan uno de los pilares fundamentales de cualquier institución castrense y que, para el caso de las Fuerzas Militares, se orientan al cabal cumplimiento de la Misión Constitucional." 
"Esta norma que debe ser interpretada de forma sistemática con los artículos 2 y 6 Superior, lo que sugiere una posición de garantía por Institución y Organización en quienes fungen como militares para proteger a todas las personas residentes en Colombia en su vida, honra, bienes, derechos y libertades, orientando toda su actividad de instrucción y entrenamiento, logístico administrativa, de servicios de guarnición, de régimen interno, operacional, etc., a la defensa de la soberanía, la independencia, la integridad del territorio nacional y del orden constitucional. Presupuestos de tal magnitud hacen que se llene de contenido el concepto servicio que se pretende proteger por vía de lo consagrado en el Título II del Código Penal Militar. (Tribunal Superior Militar, Proceso 156602-7040-XIV-402-EJC, p. 9).

Posición que presenta plena concordancia con los pronunciamientos de la Corte Constitucional que señala:

En efecto, la noción de servicio militar o policial tiene una entidad material y jurídica propia, puesto que se patentiza en las tareas, objetivos, menesteres y acciones que resulta necesario emprender con miras a cumplir la función constitucional y legal que justifica la existencia de la fuerza pública. (Corte Constitucional, Sentencia C-358, 1997).

Respecto de la interpretación del magistrado militar, atendiendo los mandatos de los artículos segundo y sexto constitucional, se ha aceptado que el servidor público tiene precisamente la función de servir y que también es responsable por las conductas antijurídicas cometidas por acción o por omisión, pero se hace necesario distinguir la naturaleza de las conductas para poder atribuirles esa facultad de convertirlas en condicionantes de la posición de garante de los militares, mediante la realización de un estudio sistemático del ámbito particular de la sociedad militar y de las atribuciones que el Estado les ha otorgado, de la situación sociopolítica y de las formas de relación que el ejercicio de la acción coactiva armada precisa con los particulares.

La aplicación de la norma penal y disciplinaria en los miembros de las Fuerzas Militares parte de la limitación que le determina la situación presente de la persona frente al servicio militar. La calidad de militar no la da automáticamente el ingreso en el servicio militar, pues tanto oficiales como suboficiales deben realizar el proce- 
so administrativo de capacitarse mediante la instrucción y el entrenamiento en las escuelas militares respectivas y, solo terminado dicho proceso, alcanzan el grado y la condición de militar. Igual proceso realiza el soldado hasta el juramento de bandera.

Las conductas plenamente identificadas en el tipo, como merecedoras de una acción penal o disciplinaria, bien pueden presentar posibilidad de discusión por su ubicación dentro de una u otra norma, especialmente si corresponden a los tipos de omisión. Así por ejemplo, mantenerse instruido, entrenado, capacitado para el ejercicio de la guerra es una obligación ética y de carácter administrativo (de requisitos para el ejercicio del cargo o la función) del militar en relación con la seguridad de los colombianos, pero a nadie puede imputársele delito alguno por estar mal instruido, entrenado o capacitado, quedando ello en una consideración que solo puede ser sancionada en el ámbito disciplinario y que, según las normas de carrera, es causal de retiro del servicio.

Habría en ese caso, una omisión por el desconocimiento consciente de la obligación reglamentaria de estar bien preparado y entrenado, pero hay serias dificultades procesales para imputar esa causa sobre el resultado de una operación militar, dadas las múltiples circunstancias que pueden influir en él, como la capacidad de las armas, la capacidad de inteligencia militar, la participación de la tecnología, los factores climáticos y hasta se podría incluir la misma suerte.

En el mismo sentido lo acepta la Fiscalía General de la Nación cuando hace relación a la Regla Rendulic para dar justificación a la necesidad de permitir a los militares cierto grado de discrecionalidad a causa de factores como "incertidumbres, como la fuerza numérica del enemigo, la calidad del equipamiento, el espiritu de combate, la eficiencia de sus comandantes y la incertidumbre de sus intenciones"

El Código Penal Militar hace imputables las conductas de desobediencia e insubordinación como ataques al bien jurídico de la disciplina y el abandono del puesto y del servicio (no se hace referencia a la deserción) como lesivos del bien jurídico del servicio, colocando sobre ellas la posición de garante de una parte por la prestación

6 Fiscalía General de la Nación, Directiva No. 003 de 17 de diciembre de 2015, citando a Tribunal Penal Militar de Núremberg, Estados Unidos vs Wilhelm List en Casos de Crímenes de guerra ante el Tribunal Penal Militar de Núremberg, No. 10, Vol. XI TWC (1948) P. 1297 
del servicio y de otra por la protección de la vida, la integridad y la libertad de las personas, a pesar de ser todas ellas actividades administrativas por las que podría existir el castigo administrativo, no el penal, salvo que las mismas se presenten en cumplimiento de operaciones militares, en áreas geográficas afectadas por un conflicto armado o en estado de guerra.

Surge de algunos de estos casos la posibilidad de discutir si la norma debe nacer únicamente de la voluntad autoritaria del Estado o como instrumento de poder dominante del mismo, todavía cercano a la concepción del Estado como soberano y de gobernantes como representantes del poder de este y no como delegados de los asociados y, por ende, de sus mandantes.

\section{LA ANTIJURICIDAD}

Manifiesta el Código Penal Militar:

"Artículo 17. Antijuridicidad. Para que una conducta típica sea punible se requiere que lesione o ponga efectivamente en peligro, sin justa causa, el bien jurídicamente tutelado por la ley penal” (Ley 1407, 2010).

La competencia legislativa que la Constitución Política otorga al Congreso, mediante los artículos 114 y 150 para legislar en materia penal, tiene límites en los derechos fundamentales como la libertad y el debido proceso, entre otros, por lo que se debe considerar una extralimitación en sus atribuciones al momento de imponer una carga punitiva con restricciones a la libertad por conductas que, con igual rigor, pero sin dicha afectación, pueden ser tratadas por el Régimen Disciplinario.

El bien común es el mismo bien jurídico tutelado, aunque es comprensible el interés del Estado en proteger la prestación del servicio militar y en garantizar la protección de la vida de sus servidores, es incomprensible como no delimita la ponderación permitida a ciertas conductas, según el principio de proporcionalidad entre la libertad de sus autores y la afectación real a los bienes jurídicos protegidos, vale decir que no se tiene en cuenta la realidad social y política para determinar, en el caso de la jurisdicción penal militar, una diferencia entre lo penal y lo disciplinario, donde la 
Justicia Penal Militar adquiera plena vigencia durante los tiempos de guerra o conflicto armado y en las zonas de operaciones que a la misma autoridad militar se le delimita, de la acaecida en tiempo o zonas de paz, donde es casi inocuo el daño que con algunos delitos o faltas se deteriora al Estado.

Se hace necesario conocer en forma clara la idea de bien jurídico, que según lo señalado por Hans-Heinrich Jescheck (1993):

"Los bienes jurídicos son intereses vitales de la comunidad a los que el derecho penal otorga su protección. Protección significa que mediante normas jurídicas se prohiben con amenaza de pena las acciones idóneas para menoscabar de modo particularmente peligroso los intereses vitales de la comunidad. El tipo arranca así de la norma, y la norma, del bien jurídico” (p. 231)

Respecto del Código Penal Militar, vale decir que no se encuentra la materialización del daño al bien jurídico de la disciplina o del servicio en delitos como la desobediencia o el abandono del puesto, sin embargo se les ha entregado un valor superior bajo la presunción del daño a la prestación del servicio militar, que se castiga hasta con tres (3) años de prisión. Igual consideración se tiene respecto del delito del centinela, donde a la acción (por ejemplo, dormir) el operador judicial suma un resultado presunto en consideración a la posición de garante (riesgo sobre la vida) para llegar a una sanción con privación de la libertad por lo que pudo llegar a suceder, tan incierto que es imposible demostrarlo.

Aún permanece en la Constitución y en la ley, la obligatoriedad del servicio militar, pero no en el espíritu del intérprete de la Carta que en cada fallo ratifica que, además de las exenciones, también se puede eludir con las objeciones o con la no presentación voluntaria a definir la situación militar, luego, entonces, ha dejado de ser obligatorio, en la práctica ha desaparecido la necesidad de protegerlo jurídicamente pues la obligación de la defensa es del Estado y no de los ciudadanos, razón por la cual es aquel quien debe contratar a quienes van a prestar el servicio y la relación jurídica cambia en forma fundamental.

Acerca de la antijuricidad Velásquez (2010) hace referencia al injusto personal de la que manifiesta como postura más coherente la que permite aglutinar el desvalor de la acción con la del resultado. Al respecto expresa: 
"El injusto está conformado tanto por el desvalor de acción (dentro del cual se examinan las condiciones objetivas del autor, los elementos subjetivos del injusto, el dolo y la culpa) como el desvalor del resultado (que comprende la lesión o puesta en peligro del bien jurídico y el modo externo con el que se produce esa lesión o puesta en peligro” (p. 462)

Visto de esta manera, lo que se ve es que el injusto o ilícito en los delitos contra el servicio y contra la disciplina no se determinan por la gravedad de la conducta o el acto, sino por el posible resultado a que conduzcan, que estando definido por el legislador como daño al bien jurídico de la vida o del servicio (es decir contrario al interés general), convierte el acto en doloso, sin ninguna posibilidad de alegato en contrario, con lo cual cumple el presupuesto de contradictorio frente a la norma jurídica y merecedor de la sanción penal.

Sin desconocer que el Estado da a su sistema penal unos conceptos de bien jurídico, acordes con los intereses que la realidad social le posibilita para garantizar la convivencia y el funcionamiento de su sistema social, parece que la tendencia de la Justicia Penal Militar está orientada en el sistema, inseparable del bien jurídico tutelado disciplina, que Galán (2010) relaciona así:

"El delito será una desobediencia a la Ley, un desacato al legislador, un desaire a la autoridad estatal. Las posiciones inmanentes del bien jurídico son acríticas, tienden a confundir el resultado con la conducta misma y la conducta con el dolo, es decir, que, dada la conducta, el dolo se considera implícito y por consiguiente demostrado por la misma conducta y con ella, cumplido también comprobado el resultado no deseado por el legislador" (p.124).

\section{LA CULPABILIDAD EN LA JUSTICIA PENAL MILITAR}

Martínez Escamilla, M., Martín Lorenzo M. y Valle Mariscal de Gante, M. (2012) al referirse a la culpabilidad en el ámbito penal han manifiestan:

"En un Estado respetuoso del fuero interno del sujeto, queda claro que con culpabilidad penal no se alude a un juicio moral sobre el autor, sino a las 
condiciones que permiten exigirle responsabilidad por un hecho individual prohibido, no por su forma de ser o su ideología o moral” (p. 320)

El Código Penal Militar describe la culpabilidad en el artículo 18, que "solo se podrá imponer penas por conductas realizadas con culpabilidad. Queda erradicada toda forma de responsabilidad objetiva” (Ley 1407, 2010).

La definición remite exclusivamente a la conducta, de manera que el operador judicial deberá esclarecer si en su ejecución se presentó la culpa o el dolo, además, deberá entender que dicha conducta es exclusivamente personal, del fuero individual del autor.

Reitera Galán (2010) que: "La culpabilidad es un concepto político-jurídico que pone al individuo frente al Estado, para lo cual es indispensable que exista el reconocimiento de su autonomía e inocencia inherentes a su dignidad" (p. 146).

El concepto político-jurídico al que se hace referencia debe entenderse, entonces, como el relacionado con los presupuestos y condiciones que fijan las normas jurídicas y los que entregan los hechos en que la conducta delictiva puede imputársele a un autor, donde el componente político habrá de estar señalado por las condiciones sociales en que se desarrolla su vida, razón por la cual podrá haber igualdad en la culpabilidad entre iguales y desigualdad respecto de desiguales, vale decir, que en la culpabilidad habrá de tenerse en cuenta el ámbito social en que se presenta el comportamiento, que entratándose de la Justicia Militar, debe tener como lógica distinción los estados de paz y de guerra o conflicto.

\section{LA DOCTRINA EN LOS FALLOS DE LA JUSTICIA PENAL MILITAR}

Los ciudadanos en uniforme poseen un comportamiento social distinto del común, que incluye no solo su organización en comunidades cerradas que obligan casi al contacto único con otros similares, sino también un lenguaje particular que a veces contiene términos técnicos que confunden a aquellos que no han tenido contacto con el estamento militar. Para estas personas estar en servicio es estar incorporado a la vida militar, que es igual a tener la condición de militar o estar prestando el servicio 
militar, mientras estar de servicio es ejecutar una tarea o misión temporal designada por sus comandantes como ser centinela, comandante de guardia u oficial de servicio,

El Tribunal Superior Militar (Proceso 1560 54-4451-XIV-340 EJC) manifiesta que forma parte del servicio toda actividad administrativa, logística, de entrenamiento e instrucción, bajo la premisa de que los reglamentos militares forman parte de las normas y no pueden ser desconocidos por el legislador, lo cual coloca a la disciplina sólo para la relación interpersonal y privada entre los militares.

En primer lugar, su concepto se ajusta a la antigua costumbre militar que convertía al inferior no en subalterno sino en súbdito y tenía su máxima expresión cuando en las ceremonias militares de posesión de los comandantes se anunciaba, de acuerdo con el Reglamento de ceremonial para las Fuerzas Militares (1999), que:

"El órgano ejecutivo por Decreto No. _ ha nombrado (trasladado o destinado) al seńor _ _ (grado y nombres) al cargo de _ (nombre y número de la unidad o cargo), en tal virtud, todo el personal lo obedecerá, acatará y respetará en todos los actos del servicio como fuera de él” (p. 77).

Con ello, se está rompiendo toda consideración de igualdad entre el superior y los subalternos, como personas al interior de la sociedad, fuera del servicio militar.

Dentro de la especie del servicio en el género de la obediencia, el Código Penal Militar, en sus artículos 97 y 98, contempla los delitos de desobediencia de personal retirado y de reservistas, respectivamente. También, en clara contravención de los principios constitucionales de la prohibición contenida en el Código de Justicia Penal Militar (2010) de juzgar a civiles, aun cuando el país se encuentre en desarrollo de un Estado de excepción, teniendo en cuenta que unos y otros son ciudadanos en goce pleno de sus derechos civiles.

En segundo lugar, y no más importante, se establece que el Tribunal Superior Militar desconoce criterios del derecho administrativo y de la clasificación de las disposiciones legales. Considera este Tribunal Militar que todos los reglamentos militares son equiparables a los de operaciones, que refieren a la ejecución de verdaderas operaciones administrativas con las que se producen resultados respecto de la relación con los particulares, vale decir, que consideran igual el reglamento de servicio de 
guarnición o el de régimen interno, con el de combate de contraguerrillas o con el manual de derecho operacional. Este punto de no diferenciación afecta el servicio de justicia de las Fuerzas Militares.

El reglamento de servicio de guarnición o el de régimen interno señalan las actividades administrativas que deben cumplirse para el normal funcionamiento de la unidad militar, como señalar las funciones de los comandantes de los diferentes servicios, la hora y actividades de la diana, la instrucción y entrenamiento y, aún, el descanso, que en nada afectan el bien jurídico protegido del servicio de defensa estatuido constitucionalmente y bien diferente de lo que ordena el manual de derecho operacional que, de no seguirse en la ejecución de las operaciones, implica graves consecuencias legales para los mandos y los ejecutores.

Manifestar, como lo hace el Tribunal Superior Militar, que toda actividad administrativa es un acto del servicio que el Estado protege como bien jurídicamente tutelado del servicio mediante la posición de garante por la razón de que es un acto necesario para emprender el cumplimiento de la función constitucional es apenas una razón hipotética respecto de cualquier miembro de las Fuerzas Militares, pues nadie puede asegurar que la guerra se habrá de presentar durante el tiempo de prestación de su servicio. Además, tampoco se puede aseverar que por falta de entrenamiento no se defiendan los intereses del Estado, quizás se defiendan mal, pero, de igual manera, puede suceder con quienes han recibido el entrenamiento. En síntesis, no entrenarse convenientemente para cumplir su misión será una falla ética, pero no un delito.

Tampoco asiste razón al decir que las operaciones militares de defensa empiezan con el entrenamiento, porque ellas inician legalmente con la emisión de las órdenes de operaciones. Corresponde al comandante militar elegir entre los hombres mejor preparados para el cumplimiento de una misión y, a partir del momento, establecer las responsabilidades a que haya lugar por el cumplimiento cabal de las funciones y las instrucciones. Será responsable el comandante cuando elija entre sus hombres aquellos que no han tenido entrenamiento, pero también ocurre la posibilidad de la misma responsabilidad en quien conociendo su incapacidad asume el riesgo y acepta la orden.

Por otra parte, hay un claro desconocimiento de la doctrina militar para la determinación de la tipología de los delitos, que no puede ser la misma durante los estados de 
paz o de guerra, tampoco podrá ignorarse que las guerras pueden ser totales, parciales o limitadas, pero en Colombia lo que se ha reconocido es un conflicto interno que se desarrolla en zonas geoestratégicas, es decir, en territorios de importancia para el cumplimiento de sus objetivos económicos. De esta manera, abandonar el servicio en la guerra tiene una connotación bien diferente a hacerlo durante el desarrollo de un conflicto o en el tiempo de paz.

El argumento de la guerra no declarada en el país para agravar la situación de los militares que incumplan con sus obligaciones bajo una legislación propia de un Estado en guerra es inapropiado, pues no se trata de una guerra total, no toda la población participa en ella y, por supuesto, los riesgos que se atribuyen como consecuencia de ciertas conductas no son más que hipótesis de imposible comprobación. Otro caso diferente es que en cumplimiento de una orden de operaciones se incumplan las funciones generales que competen a cada miembro de la estructura organizacional ejecutante.

El ejemplo es el del delito del centinela, mencionado en el Código de Justicia Penal Militar (2010), en el cual se castiga a: "quien que se duerma, se embriague o se ponga bajo los efectos de sustancias estupefacientes o psicotrópicas, o falte a las consignas especiales que haya recibido, o se separe de su puesto, o se deje relevar por quien no esté legítimamente autorizado" (art. 112).

En tipo penal se puede visualizar la existencia de la aceptación doctrinal del Tribunal Superior Militar hacia el delito de acto, entendiendo este como aquel que "permite castigar al hombre por lo que hace, por su conducta social, y no por lo que es, ni por lo que desea, piensa o siente" (Sentencia C-365, 2012), razón por la cual se sanciona el acto de dormir o de embriagarse, sin tener en cuenta un resultado que puede o no sucederse, aunado a lo anterior la doctrina no exige la comprobación del dolo en la ejecución de la conducta, es decir, la voluntad del autor encaminada a lesionar el bien jurídicamente tutelado. Sin embargo, interpretar esta conducta de una manera simple es negar la misma condición humana del agente, porque su actuar puede estar influenciado por circunstancias exógenas, como una enfermedad que doblegue la voluntad del centinela y lo duerma.

Por tal razón, es necesario diferenciar el lugar donde se está prestando el servicio, pues no es lo mismo realizar la labor de centinela en la ejecución de una operación 
militar o en una unidad ubicada en zona de alto riesgo o en las conocidas zonas rojas, a diferencia de los cantones militares situados en ciudades capitales y poblaciones donde no se hace manifiesta la situación de conflicto. Se hace necesario, para no ser injustos, que se diferencie lo correspondiente a la Justicia Penal Militar y al Régimen Disciplinario para casos como los citados.

La Corte Constitucional ha sostenido que el procedimiento penal debe ser la última razón en el derecho sancionador y que se deben agotar, previamente, todos los controles previstos, inclusive de orden administrativo, antes de llegar a los estadios penales. Así lo ha sostenido dicha corporación:

"La Corte ha sostenido que el derecho penal se enmarca en el principio de mínima intervención, según el cual, el ejercicio de la facultad sancionatoria criminal debe operar cuando las demás alternativas de control han fallado. Esta preceptiva significa que el Estado no está obligado a sancionar penalmente todas las conductas antisociales, pero tampoco puede tipificar las que no ofrecen un verdadero riesgo para los intereses de la comunidad o de los individuos; como también ha precisado que la decisión de criminalizar un comportamiento humano es la última de las decisiones posibles en el espectro de sanciones que el Estado está en capacidad jurídica de imponer, y entiende que la decisión de sancionar con una pena, que implica en su máxima drasticidad la pérdida de la libertad, es el recurso extremo al que puede acudir el Estado para reprimir un comportamiento que afecta los intereses sociales. En esta medida, la jurisprudencia legitima la descripción típica de las conductas sólo cuando se verifica una necesidad real de protección de los intereses de la comunidad. De allí que el derecho penal sea considerado por la jurisprudencia como la última ratio del derecho sancionatorio" (Sentencia C365, 2012).

Esta misma diferenciación, con argumentos parecidos, es aplicable al delito de abandono del puesto (Ley 1407, 2010, art. 105), entendido como función de Comando o de cargo, que solo debería ser penada cuando se trate del acto en lugares donde se esté desarrollando la guerra o el conflicto.

La organización de las Fuerzas Militares es jerarquizada y detrás de cada comandante hay un segundo capaz de ejercer el cargo cuando la situación así lo determine, de 
manera que cuando un militar deja su cargo o lo abandona comete un acto de descortesía al no solicitar por escrito o verbalmente su retiro, pero no siempre coloca en peligro el servicio militar ni la disciplina, pues, aunque se diga lo contrario, los subalternos, incluidos sus compañeros de curso y grado, inclusive con un puesto menos de antigüedad en la jerarquía, actúan ansiosos esperando el retiro de los más antiguos para subir en el escalafón, presentándose muy raras veces una renuncia masiva o solidaria. La razón de ello es que la carrera militar es la única en donde ingresan unos funcionarios que desarrollan una competencia para alcanzar la máxima jerarquía institucional, cosa que no ocurre en ningún otro estamento del Estado, es decir funciona bajo la modalidad de ascensos.

\section{EXCESOS Y DEFECTOS}

El Código Penal Militar, en su artículo 97, tipifica el delito de desobediencia de personal retirado que sanciona con uno (1) a dos (2) años de prisión cuando no se presente ante decretos de movilización o de llamamiento especial al servicio. Contradictorio, frente al mandato constitucional que prohíbe el juzgamiento de civiles por la Justicia Penal Militar ${ }^{7}$ y contra sus propios mandatos que señalan que en ningún caso podrán investigarse o juzgarse a civiles por la Justicia Penal Militar ${ }^{8}$, es un exceso en la legislación militar.

El Estatuto del Personal de Oficiales y Suboficiales de las Fuerzas Militares contempla, además de las sanciones administrativas, las penales, sin hacer ninguna consideración especial a su derecho de objetar dicho llamamiento:

"Artículo 142. Llamamiento especial al servicio. El Gobierno y los Comandos de Fuerza respectivamente, podrán llamar en forma especial al servicio a los Oficiales y Suboficiales retirados en forma temporal, en cualquier tiempo para

7 Constitución Política de Colombia, art. 213. “(...) En ningún caso los civiles podrán ser investigados o juzgados por la justicia penal militar".

8 Código de Justicia Penal Militar, Ley 1407 de 2010, art. 5. "Investigación y juzgamiento de civiles. En ningún caso los civiles pueden ser investigados o juzgados por la justicia penal militar". 
fines de entrenamiento o para satisfacer necesidades orgánicas de las Fuerzas o hacer frente a las exigencias de la seguridad nacional.

Los Oficiales y Suboficiales que infringieren lo dispuesto en este artículo, serán sancionados por resolución motivada del respectivo Comandante de Fuerza con multa que oscile de uno (1) a diez (10) sueldos básicos correspondientes al grado que ostenten al momento del llamamiento especial al servicio, descontable del sueldo de retiro o exigible por el Ministerio de Hacienda y Crédito Público, sin perjuicio de la acción penal correspondiente" (Decreto 1211, 1990).

También, el artículo 98 del Código Militar hace referencia al delito de desobediencia del reservista, con la diferencia sustancial consistente en que este podrá invocar para su negativa a reincorporarse al servicio, las causales de exención previstas en la ley. Como se observa el legislador y por el Gobierno desconocen, además de la imposibilidad de juzgar militarmente a los civiles, el principio de pluralismo político mediante el cual cualquier individuo puede negarse a la reincorporación al servicio militar cuando sus ideales políticos o de otra índole se enfrentan con los del Estado, de modo que el tribunal militar puede estaría participando en política. Así lo manifiesta la Corte Constitucional:

"Los rasgos democráticos y pluralistas del Estado colombiano condicionan también la legitimidad constitucional de las políticas de seguridad y defensa, pues implican que esas estrategias deben respetar el pluralismo y la participación democrática, así como la autonomía de la sociedad civil, por lo que no es válido, ni siquiera en las más graves crisis institucionales, intentar que ciertos aparatos del Estado, como el ejecutivo, absorban la sociedad para ponerla integralmente a sus órdenes" (Corte Constitucional, Sentencia C-251, 2002).

De otra parte, sin la existencia de una modificación constitucional que así lo consienta, el legislador militar ha permitido que el juez ordinario defina la situación militar de los colombianos, cuando ante la objeción de conciencia y ante los actos de reclutamiento forzoso realizados por las Fuerzas Militares las decisiones de los jueces tienen prioridad sobre las determinaciones constitucionales y de la ley. 
La Constitución Política de Colombia señala la obligatoriedad del servicio militar y faculta a la ley para determinar las condiciones mediante las cuales se eximen algunos ciudadanos de su prestación, así:

"Artículo 216. La fuerza pública estará integrada en forma exclusiva por las Fuerzas Militares y la Policía Nacional.

Todos los colombianos están obligados a tomar las armas cuando las necesidades públicas lo exijan para defender la independencia nacional y las instituciones públicas.

La Ley determinará las condiciones que en todo tiempo eximen del servicio militar y las prerrogativas por la prestación del mismo" (Const., 1991).

En consonancia con lo anterior, mediante la ley define la facultad de las propias Fuerzas Militares para el servicio de Reclutamiento y Movilización, con el fin de definir la situación militar de los asociados del Estado: ${ }^{9}$

"Artículo 9. Funciones del Servicio de Reclutamiento y Movilización. Son funciones del Servicio de Reclutamiento y Movilización:

a. Definir la situación militar de los colombianos;

b. Dirigir y organizar el sistema de reemplazos en las Fuerzas Militares;

c. Efectuar la movilización del personal con fines de defensa nacional” (Ley 48, 1993, art. 9).

A pesar de este enunciado normativo, la Corte Constitucional en la Sentencia T-455 de 07 de julio de 2014, MP. Luis Ernesto Vargas Silva, como intérprete de la Constitución ha decidido que la objeción de conciencia se constituya en un derecho fundamental, eximente de la prestación del servicio militar y que las batidas o redadas para conducir a las personas a las instalaciones de reclutamiento para definir su situación militar sean prohibidas, excepto para personas que habiendo sido examinadas sean

9 Ley 48 de marzo 03 de 1993, Por la cual se reglamenta el servicio de Reclutamiento y Movilización, art. 9 
consideradas aptas y tengan condición de remisos por no presentarse a prestar la obligación, de manera que el juez ordena al reclutador expedir la tarjeta de reservista, tomando la decisión que corresponde por ley a la autoridad militar y dejando de paso la obligación de prestar el servicio militar, reducida a un deber relativo que puede dejar de cumplirse.

No ha producido el legislador militar en sus decisiones conceptos que se conviertan en doctrina respetable y respetada por las demás Cortes, por emanar de tribunales y magistrados especializados en la defensa. La Constitución y la ley manifiestan obligatoria la definición de la situación militar de los colombianos y corresponde a la Fuerza Pública colaborar en la ejecución de la ley, es decir obligar su cumplimiento, inclusive con la fuerza, situación que está desconociendo el juzgador ordinario, haciendo de paso una consecuente debilitación de la defensa del Estado que, sin capacidad económica para decidir por un servicio profesional, permite que sus asociados actúen con voluntariedad ante la obligación.

En relación con lo anterior, el Consejo de Estado - Sala de lo Contencioso Administrativo - Sección Tercera (25 de febrero de 2009), Magistrada Dra. Myriam Guerrero de Escobar, advierte que:

"Los soldados que prestan el servicio militar en calidad de conscriptos, es decir, aquellos que son reclutados de manera obligatoria, soldados regulares, bachilleres campesinos, etc., no pueden ser expuestos al fuego enemigo, señalando que deben ser entrenados para desarrollar actividades de bienestar social y tareas destinadas a la preservación del medio ambiente y la conservación ecológica. Por ello, el servicio alternativo con funciones sociales del servicio militar obligatorio es una solución que se hace compatible con la obligación de prestar el servicio al Estado y a la comunidad sin menoscabar las libertades individuales”.

\section{Conclusiones}

El Código Penal Militar y el Reglamento de Régimen Disciplinario para las Fuerzas Militares, de acuerdo con las normas doctrinarias del derecho, se han elaborado te- 
niendo en cuenta no solo las necesidades del servicio de defensa de la sociedad, sino también las de supervivencia del Estado aun a costa de sus asociados.

En su facultad de construcción de las normas, el Estado puede llegar inclusive a desconocer el poder soberano del pueblo, atribuyendo condiciones de imperio sobre sus asociados, como ha quedado evidenciado de la supremacía de la institución sobre la persona sobre todo en regímenes castrenses como el Colombiano.

Los Tribunales Militares desconocen su propia importancia y demuestran poca preocupación por sentar doctrina para convertir en dogmática y precedente sus decisiones, haciendo intrascendente su función como tribunal especializado.

El afán del Estado y de los mandos militares por el mantenimiento de un statu quo que permita el ejercicio del mando militar bajo formas de relación comandante-súbdito y no líder-subalterno, genera el traslado de la norma disciplinaria a la penal, con las consecuentes implicaciones de afectación a la libertad de quienes no se ajusten a sus condiciones.

El Estado también traslada a los militares la responsabilidad de proveer la defensa de la nación y la función de castigar a quienes ejercen su derecho a, por el contrario, ser defendidos por el Estado.

De acuerdo con el contenido y las conclusiones generales obtenidas del análisis, se hace previsible que, aun cuando cambie la condición social de conflicto a un estado de paz, no se generarán cambios en las normas jurídicas militares. La experiencia ha demostrado que la implementación de cambios normativos, en ciertas ocasiones, es lenta debido a la resistencia al cambio y a la adaptación y complejidad de las nuevas disposiciones que sean sugeridas.

\section{REFERENCIAS}

Bobbio, N. (2006). Estado Gobierno y Sociedad. México: Fondo de Cultura de México.

Cámara de Diputados del H. Congreso de la Unión (31 de agosto de 1993). Código de Justicia Militar. Última reforma publicada en el Diario Oficial de la Federación 13 de 
junio de 2014. Consultado el 30 de noviembre de 2015 en: www.diputados.gob.mx/ LeyesBiblio.

Centro de Documentación e Información, Ministerio de Economía y Finanzas Públicas, Código de Justicia Militar, Ley 26394 de 26 de agosto de 2008, infoleg.mecon.gov.ar, recuperado el 10 de diciembre de 2015

Constitución Política de Colombia, (1991)

Consejo de Estado. Sala de lo Contencioso Administrativo, Sección Tercera. (MP. Dra. Myriam Guerrero de Escobar; 25 de febrero de 2009).

Corte Constitucional. Sentencia C-358 de 1997. (MP. Eduardo Cifuentes Muñoz; agosto 5 de 1997).

Corte Constitucional. Sentencia C-769 de 1998. (MP. Antonio Barrera Carbonell; diciembre 10 de 1998).

Corte Constitucional. Sentencia C-599 de 1999 (MP. Alejandro Martínez Caballero)

Corte Constitucional. Sentencia C-404 de 2001. (MP. Marco Gerardo Monroy Cabra; abril 19 de 2001).

Corte Constitucional. Sentencia C-251 de 2002. (MP. Clara Inés Vargas y Eduardo Montealegre Lynnet; abril 11 de 2002).

Corte Constitucional. Sentencia C-818 de 2005. (MP. Rodrigo Escobar Gil; agosto 9 de 2005).

Corte Constitucional. Sentencia C-605 de 2006. MP. (MP. Marco Gerardo Monroy Cabra; agosto 01 de 2006).

Corte Constitucional. Sentencia C-121 de 2012. (MP. Luis Ernesto Vargas Silva; febrero 22 de 2012).

Corte Constitucional. Sentencia C-365 de 2012. (MP. José Ignacio Pretelt Chaljub; mayo 16 de 2012).

Corte Constitucional. Sentencia T-455 de 2014. (MP. Luis Ernesto Vargas Silva; julio 07 de 2014).

Corte Suprema de Justicia. Sala de Casación Penal. Rad. 12878 de 1989 (M.P. Jorge Aníbal Gómez Gallego). 
Decreto 1211 de 1999.

Ferrari, V. (1989). Funciones del Derecho. Madrid: Editorial Debate.

Fiscalía General de la Nación, Directiva 003 de 17 de diciembre de 2015, citando a Tribunal Penal Militar de Núremberg, Estados Unidos vs Wilhelm List en Casos de Crímenes de guerra ante el Tribunal Penal Militar de Núremberg, No. 10, Vol. XI TWC (1948)

Galán Castellanos, H. (2010). Teoría del delito. Escuela Judicial Rodrigo Lara Bonilla.

García Amado, J. (2012). Responsabilidad jurídica, Eunomia. Revista en Cultura de la Legalidad (1)Septiembre 2011-Febrero 2012.

Hans-Heinrich, J. (1993). Tratado de Derecho penal, parte general, cuarta edición. Granada: Editorial Comares.

Ley 734 (2002). Por la cual se expide el Código Disciplinario Único. Febrero 5 de 2002. DO: 44.699 .

Ley 48 (2003). Por la cual se reglamenta el servicio de Reclutamiento y Movilización. Marzo 3 de 1993. DO: 40.777.

Ley 836 (2003). Por la cual se expide el Reglamento del Régimen Disciplinario para las Fuerzas Militares. Julio 16 de 2003. DO: 45.251.

Ley 1407 (2010) Por la cual se expide el Código de Justicia Penal Militar. Agosto 17 de 2010. DO: 47.804 .

Martínez Escamilla, M., Martín Lorenzo M. y Valle Mariscal de Gante, M. (2012) Derecho Penal. Introducción. Teoría jurídica del delito. Universidad Complutense de Madrid

Ministerio de Defensa Nacional. (s.f). Justicia Penal Militar. Información Institucional. Recuperado el 24 de agosto de 2015 de: www.justiciamilitar.gov.co

Ministerio de la Presidencia, Gobierno de España, Agencia Estatal Boletin Oficial del Estado (2015) Ley orgánica 14 de 14 de octubre de 2015. Código Penal Militar.

Navas Corona, A. (2003) Tipicidad y derecho penal. Enfoque del Código Penal Ley 599 de 2000. Bucaramanga: SIC Editorial.

Procuraduría General de la Nación (2011). Concepto 5212 de 07 de septiembre de 2011. Alejandro Ordoñez Maldonado. Recuperado de: www.procuraduría.gov.co. 
Via Inveniendi et Iudicandi

Tribunal Superior Militar (s.f) MP. Suárez Aldana Camilo Andrés, Proceso 156500-730-XIV-392- PNC.

Tribunal Superior Militar (s.f) MP. María Paulina Leguizamón Zárate, Proceso 1560 544451-XIV-340 EJC.

Velásquez, F. (2010). Manual de Derecho Penal Parte General, Cuarta Edición. Ediciones Jurídicas Andrés Morales. 